\title{
Lung elastic recoil and reduced airflow in clinically stable asthma
}

\section{S MCCARTHY AND M SIGURDSON}

From the Department of Medicine, University of Manitoba, Respiratory Division, Clinical Investigation Unit, W'innipeg, Manitoba, Canada

ABSTRACT Lung volumes, maximum expiratory flow rates, and static volume-pressure curves $\omega_{\perp}^{\sim}$ were measured in 16 patients with clinically stable asthma. It was found that flow rates were reducedin in such patients because of the combined effects of reduced elastic recoil (transpulmonary pressure) $)^{\infty}$ and intrinsic diseases of the airways. In nine patients treated with an aerosol of isoprenaline,, flow rates improved as a result of reduction in airways resistance as the static recoil pressure of the lungs fell further in those patients. The possibility is suggested that muscle tone in peripherato airways or alveolar ducts contributed to the elastic recoil measurements.

A number of studies have demonstrated that acute exacerbations of asthma may be accompanied by shifts in the pressure-volume curve of the lungs indicating reduction of elastic recoil. For example, Gold et $a l^{1}$ found that lung elastic recoil was decreased in 12 asthmatic patients before treatment. Later, Finucane et $a l^{2}$ reported that elastic retraction was decreased in 10 asthmatic subjects with reduced forced expired volume in the first second $\left(F E V_{1}\right)$. In both series, the lung recoil usually returned to baseline values when the airflow obstruction was relieved. Similar findings were reported by Mansell et $a l^{3}$ after antigen-induced asthma. However, Woolcock et $a l^{4}$ found that reduced lung elastic recoil persisted in five of 10 asthmatic subjects even when airway resistance had returned to normal. Since many patients with asthma satisfactorily controlled from a clinical standpoint (stable) have persistent airflow obstruction, we wished to determine whether there was persistent loss of lung elastic recoil in such patients which would tend to decrease expiratory flow. We also wished to examine the immediate effects of bronchodilator therapy on elastic recoil in clinically stable asthmatics.

\section{Methods}

The characteristics of 16 patients, 11 men and

Address for reprint requests: Dr DS McCarthy, Department of Medicine, University of Manitoba, Respiratory Division, Clinica Investigation Unit, Winnipeg, Manitoba, Canada.
Table 1 Age, sex, and diagnostic criteria used to select 16 patients with asthma

\begin{tabular}{|c|c|c|}
\hline Criteria & $\begin{array}{l}\text { Total group } \\
(n=16)\end{array}$ & $\begin{array}{l}\text { Isoprenaline group } \\
(n=9)\end{array}$ \\
\hline $\begin{array}{l}\text { Male } \\
\text { Female } \\
\text { Age (yr) (mean and range) } \\
\text { Positive skin tests (type 1) } \\
\text { Eosinophil counts }>400 / \mathrm{ml} \\
\text { Paroxysmal episodes }\end{array}$ & $\begin{array}{l}11 \\
5 \\
46(25-65) \\
11(69 \%) \\
11(69 \%) \\
16\end{array}$ & $\begin{array}{l}6 \\
3 \\
46(20-70) \\
6(67 \%) \\
5(56 \%) \\
9\end{array}$ \\
\hline $\begin{array}{l}\text { Bronchodilator response } \\
\text { (mean \% predicted and range) }\end{array}$ & & \\
\hline $\begin{array}{l}\text { FEV }_{1} \text { before ( } \% \text { predicted) } \\
\text { FEV }_{1} \text { after }(\% \text { predicted })\end{array}$ & $\begin{array}{l}62(49-77) \\
92(84-108)\end{array}$ & $\begin{array}{l}59(44-77) \\
89(69-107)\end{array}$ \\
\hline
\end{tabular}

five women, who were studied are shown in table 1 ; nine patients who were not dissimilaro to the entire group received aerosol isoprenaline. No effort was made to allocate patientso selectively to this group. All patients were adult non-smokers and the age distribution was similaro in both groups. The following features supported 0 the diagnosis of bronchial asthma. Reaginic mediated, wheal and flare reactions (type 1)o were obtained in the majority of patients $(69 \%$ and $62 \%$ ) on skin testing with a range of $\frac{}{\mathbb{D}}$ common allergens. Peripheral blood eosinophilia, $\stackrel{\infty}{+}$ as indicated by eosinophil counts in excess of 0 $400 / \mathrm{ml}$, was present in most patients $(69 \%$ ando $56 \%$ ). The five patients with normal counts were taking corticosteroid medication. All patients $\widetilde{D}^{\circ}$ had a history of paroxysmal episodes of wheeze and dyspnoea developing over an hour or less without symptoms of respiratory infection. Allo 
had shown reversibility of airway obstruction in that they had demonstrated at some time in the past an increase of at least $20 \%$ in $\mathrm{FEV}_{1}$ immediately after inhalation of bronchodilator. Six subjects had radiological evidence of hyperinflation while the remainder had normal chest radiographs. All subjects were outpatients at the time of the study and were deemed by their physician to be in a "stable" state. This was indicated by a satisfactory clinical state and by spirometric values which were within $10 \%$ of the patients' best efforts over the previous six months, during which three or more interval measurements were made. All patients were taking oral aminophylline $325 \mathrm{mg}$ four times per day and aerosol isoprenaline more than twice per day. Five patients were taking prednisone, 5-15 mg daily at the time of the study and had been doing so for between two and four years. Two further patients had been treated with systemic corticosteroids in the past and three patients were taking inhaled beclomethasone.

Vital capacity (VC), $\mathrm{FEV}_{1}$, and maximal expiratory flow-volume curves were measured with an automated wedge spirometer. ${ }^{5}$ Using these curves, flow rates at $90,75,50$, and $25 \%$ VC were measured. Functional residual capacity (FRC) was measured using a body plethysmograph. ${ }^{6}$ The elastic recoil of the lungs was determined with the subject seated. The static transpulmonary pressure-volume curve of the lungs was measured during interrupted vital capacity expirations; the interruptions were accomplished by occluding the mouthpiece. Transpulmonary pressure was measured as the difference between pressures measured at the mouth and in the oesophagus. Oesophageal pressure was recorded from a $10 \mathrm{~cm}$ latex balloon containing $0.5 \mathrm{ml}$ air at the end of a small polyethylene catheter which was connected to a differential strain gauge and positioned in the mid-oesophagus according to the method of Milic-Emili et al. ${ }^{7}$ The other side of the differential strain gauge was connected to a lateral pressure tap in the mouthpiece. Lung volumes were determined by integration of airflow measured at the mouth by means of a Fleisch pneumotachograph (no 3) connected to a Statham strain gauge (no 5). Normal values for lung elastic recoil and upstream resistance were those measured in the same way in 30 agematched normal non-smokers in our own laboratory.

After the above measurements, nine subjects inhaled $0.5 \%$ isoprenaline delivered by a hand nebuliser (DeVilbiss no 42 nebuliser) until they increased their pulse rates by $20 \%$ or they developed palpitations or became "shaky". All measurements were repeated within 45 minutes.

\section{Results}

Though our asthmatic subjects were in clinical remission at the time of this study, airflow obstruction was present in all patients (table 2). The maximum expiratory flow rate of $50 \% \mathrm{VC}$ was less than $80 \%$ predicted in all patients and residual volume (RV) was increased in 15 patients. Static pressure-volume curves of the lung are shown in fig 1 , volume being expressed as per cent predicted TLC. It can be appreciated that especially at high lung volume the pressurevolume relationships were in general displaced, indicating loss of recoil pressure. The pressurevolume curve for the nine patients before isoprenaline approximates more closely to the normal predicted values than those of the entire group because a number of subjects with relatively normal curves are included in the former group.

The relationship between maximum expiratory airflow and static transpulmonary pressure defines the resistance upstream from the equal pressure point. ${ }^{8}$ This relationship at 90,70 , and 50 per cent of TLC predicted is shown in fig 2 . Because of gas trapping, data were not always available at $50 \%$ and $70 \%$ predicted TLC. In these patients only data acquired at higher lung volumes is shown. Maximum flow rates were reduced in our patients; only two achieved flows exceeding $51 / \mathrm{s}$ at $90 \%$ predicted TLC. Some patients showed low flow rates despite relatively normal static recoil pressures, their curves were displaced down and to the right. In these individuals, flow rates were low primarily because upstream resistance was increased. This is well

Table 2 Lung volume and flow rates in the 16 asthmatic subjects at the time of the study

\begin{tabular}{|c|c|c|}
\hline$\% V C$ & Flow $(l / s)$ Mean $\pm S D$ & $\%$ predicted \\
\hline $\begin{array}{l}90 \\
75 \\
50 \\
25\end{array}$ & $\begin{array}{l}6 \cdot 84 \pm 2 \cdot 01 \\
4 \cdot 13 \pm 2.07 \\
2 \cdot 02 \pm 1 \cdot 08 \\
0.72 \pm 0.41\end{array}$ & $\begin{array}{l}84 \\
57 \\
40 \\
30\end{array}$ \\
\hline $\begin{array}{l}\text { FEV }_{1}(1) \\
\text { FEV } / V C(\%) \\
\text { TLC (1) } \\
\text { FRC (1) } \\
\text { RV (I) }\end{array}$ & $\begin{array}{l}2 \cdot 42 \pm 0 \cdot 91 \\
57 \pm 14 \\
7 \cdot 30 \pm 1 \cdot 4 \\
4 \cdot 10 \pm 1 \cdot 0 \\
3 \cdot 04 \pm 1 \cdot 0\end{array}$ & $\begin{array}{l}72 \\
121 \\
122 \\
152\end{array}$ \\
\hline
\end{tabular}

Mean values \pm 1 SD; per cent predicted ( $\%$ PR); airflow at 90,75 , 50 , and 25 per cent vital capacity ( $\%$ VC); total lung capacity (TLC); functional residual capacity (FRC); and residual volume (RV). 


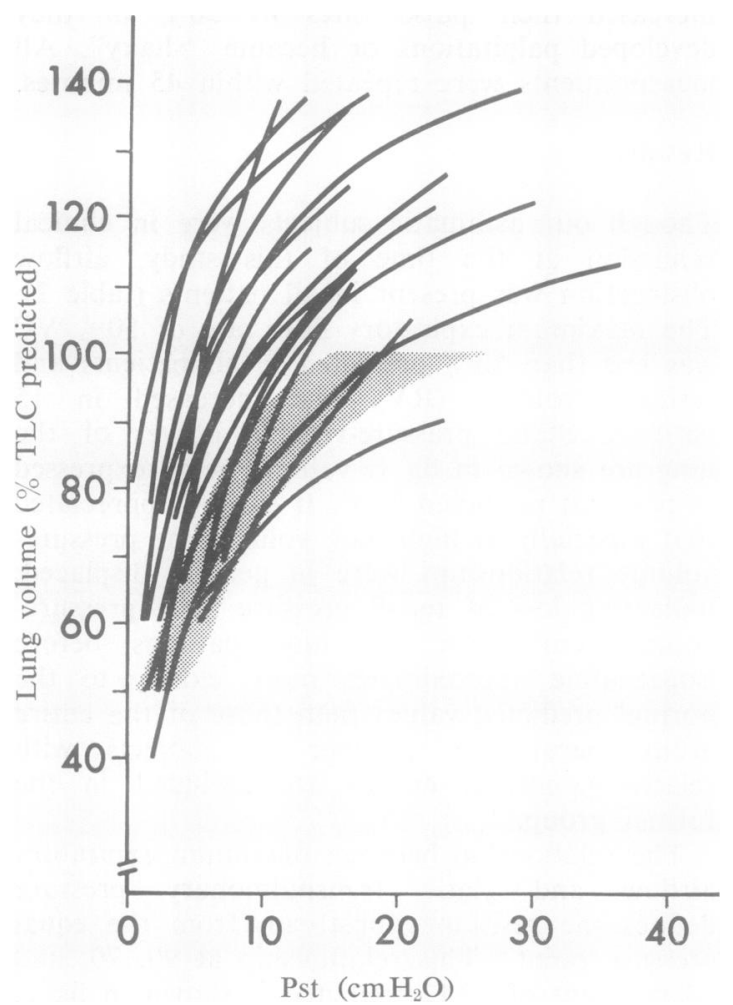

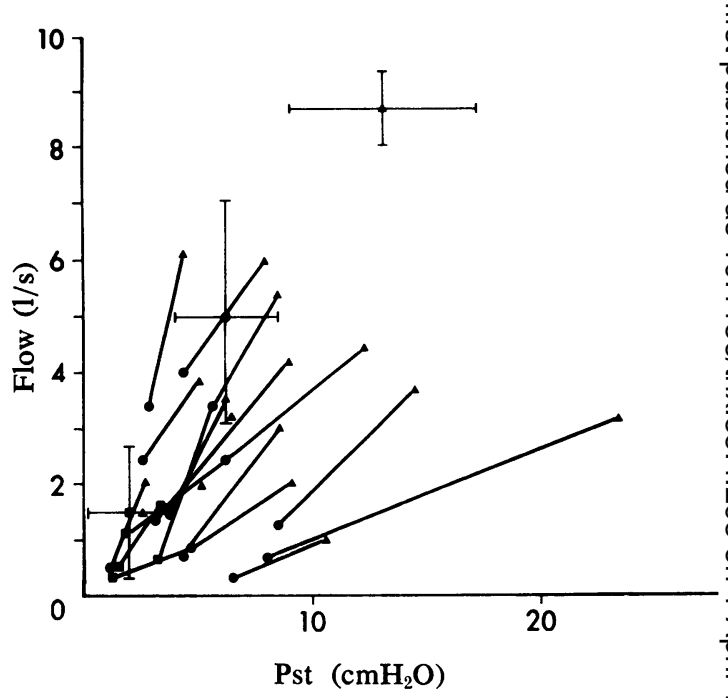

Fig 2 Relationship between maximal expiratory flow (Vmax) and static recoil pressure of the lungs in 16 patients with chronic asthma. Transpulmonary pressure on the abscissa is plotted against expiratory flow rate in litres per second on the ordinate at 90 , 70 , and $50 \%$ TLC predicted. Normal values from 30 matched subjects for pressure and flow $\pm 1 S D$ indicated by the bars at 90 (А), 70 (०), and $50 \%$ (口) TLC (predicted).

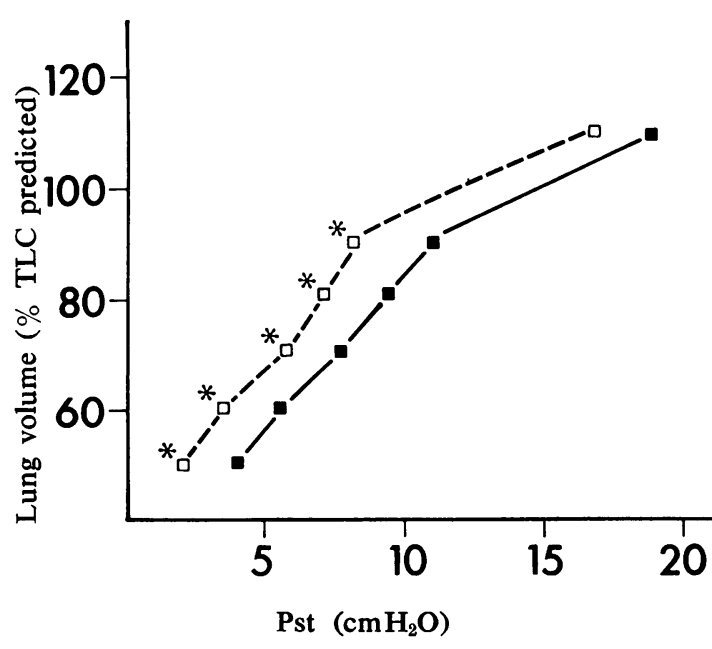

Fig 3 Static expiratory pressure-volume curves before $(\square)$ and after $(\square)$ isoprenaline.

Transpulmonary pressure on the abscissa is plotted against lung volume per cent predicted on the ordinate; $*=$ statistically significant change $(<0.05)$.
Fig. 1 Static expiratory lung pressure-volume curves from 16 patients with chronic asthma. Transpulmonary pressure on the abscissa is plotted against lung volume as per cent total lung capacity predicted. Stippled area represents five values $\pm 1 S D$ from 30 normal matched subjects. The observed value for TLC in each normal subject was designated $100 \%$ and the transpulmonary pressure calculated in decrements of $10 \%$.

seen in four of the patients. However, in more than half the patients the data fell within the predicted pressure-flow relationships, indicating that in these subjects reduction in flow rate was caused predominantly by loss of lung elastic recoil.

After use of the bronchodilator aerosol there was an increase in maximum expiratory flow (table 3) which was significant at all lung volumes except $25 \%$ VC. Figure 3 demonstrates that the lung elastic recoil was reduced after 1soprenaline. There was no significant change in lung volumes. Three patients had similar studies before and after inhalation of $6 \mathrm{mls}$ of aerosolised normal saline. No change in lung function was observed. 
Table 3 Maximum expiratory flow-volume before and af er isoprenaline

\begin{tabular}{|c|c|c|c|c|}
\hline $\begin{array}{l}\text { Per cent } \\
\text { capacity }\end{array}$ & Patients & $\begin{array}{l}\text { Flow rate } \\
\text { before }(I / s)\end{array}$ & $\begin{array}{l}\text { Flow rate } \\
\text { after }(l / s)\end{array}$ & $p$ \\
\hline $\begin{array}{l}90 \\
75 \\
50 \\
25\end{array}$ & $\begin{array}{l}9 \\
9 \\
9 \\
9\end{array}$ & $\begin{array}{l}6.35 \pm 2.16 \\
3.43 \pm 1.95 \\
1.67 \pm 1.08 \\
0.64 \pm 0.42\end{array}$ & $\begin{array}{l}7 \cdot 05 \pm 2.00 \\
4 \cdot 16 \pm 2.36 \\
1.99 \pm 1 \cdot 25 \\
0.90 \pm 0.65\end{array}$ & $\begin{array}{l}<0.01 \\
<0.025 \\
<0.025 \\
\text { NS }\end{array}$ \\
\hline $\begin{array}{l}\mathrm{FEV}_{1}(\mathrm{l}) \\
\mathrm{FEV}_{1} / \mathrm{VC}(\%)\end{array}$ & 9 & $\begin{array}{c}1.97 \pm 0.82 \\
52 \pm 10\end{array}$ & $\begin{array}{c}2 \cdot 40 \pm 0.91 \\
60 \pm 12\end{array}$ & $\begin{array}{l}<0.001 \\
<0.001\end{array}$ \\
\hline
\end{tabular}

$\mathfrak{n}=$ statistical significance of the changes.

\section{Discussion}

Our results suggest that many patients with asthma have diminished pulmonary elastic recoil even when they are in a satisfactory clinical state (fig 1). The relevance of decreased lung elastic recoil is illustrated in fig 2 which indicates that in some patients reduced airflow rates appeared largely because of decreased lung elastic recoil. However, increased airflow resistance is also important as flow rates after use of the aerosol bronchodilators increased despite lung elastic recoil decreasing or remaining unchanged (table 3, fig 3). Our finding of reduced lung elastic recoil in stable asthma is in agreement with that of Woolcock et $a l^{4}$ who found that loss of elastic recoil persisted in five of 10 asthmatics when the acute attack subsided. Finucane et $a l^{2}$ also found that in four of 10 patients decreased elastic recoil persisted for more than six weeks of remission after successful treatment of acute attacks. The latter authors suggested on the basis of their observations that some asthmatics may have permanent reduction of elastic recoil. Conversely, Gold et $a l^{1}$ found decreased elastic recoil in seven young $(<28 \mathrm{yr})$ patients with chronic asthma but recoil reverted to normal after intensive therapy and return of airway resistance to normal. Our study population differed from Gold $e t$ al ${ }^{1}$ in that our group of chronic stable asthmatics was older, in clinical remission, and already receiving what was considered adequate bronchodilator therapy though evidence of residual airflow obstruction peristed. The difference in age between the patients in our study and those studied by Gold et $a l^{1}$ is unlikely to be the total explanation as three of the five patients with persistent loss of lung elastic recoil reported by Woolcock et $a^{4}$ were young $(<30 \mathrm{yr})$. Neither is the duration of the disease likely to be important as the mean duration in our study was 7.6 years while that in the study of Gold et al ${ }^{1}$ was 11.5 yrs. It was not thought justifiable to treat our patients who were satisfactorily controlled on a clinical level with further medication in order to achieve normal airflow measurements and possible reversal of the lung elastic recoil change. From the data quoted above and reported here, it would seem that many asthmatic patients with residual or no airflow obstruction and in clinical remission have reduced lung elastic recoil.

The mechanism responsible for loss of lung elastic recoil in asthma is not known. Published reports of the morbid anatomy of asthma do not contain descriptions of pathological emphysema. Because lung recoil has been shown to decrease rapidly with the onset of an attack, changes in the amount or type of surfactant are unlikely, but it is possible that the distribution of surfactant is altered with asthma. It was suggested by Woolcock et $a l^{4}$ that prolonged steroid therapy many have contributed to reduced elastic recoil. This is an unlikely explanation as six of our patients who had never been treated with corticosteroids demonstrated decreased elastic recoil. It is also unlikely that tobacco smoking influenced the measurements as only two of our patients had ever smoked. The rapidity of the changes of lungs and chest wall recoil in the course of an asthmatic attack are compatible with a neurogenic mechanism and such a mechanism has been postulated. ${ }^{9}$ Persistence of loss of recoil in some asthmatics in complete remission reported by Woolcock $e t a l^{4}$ and by Finucane $e t a l^{2}$ is further evidence that the mechanism of loss of lung elastic recoil is complex and not well related to airway obstruction as measured by tests such as $\mathrm{FEV}_{1}$, airway resistance, or MMF.

We found that in our stable asthmatic patients inhalation of isoprenaline was associated with a further decrease in elastic recoil (fig 3 ). McFadden et $a l^{10}$ noted that elastic recoil in the mid and upper lung volumes decreased after normal subjects inhaled isoprenaline but the changes they observed were smaller than the ones we noted. Our results were similar to observations made by Colebatch ${ }^{11}$ who found that isoprenaline decreased recoil in cat lungs. He postulated that this was because it reduced smooth muscle tone in peripheral airways which contribute to lung elastic recoil. This hypothesis would explain our findings. A recent publication by Laitinen et al, ${ }^{12}$ describing an increase in lung recoil in normal subjects after intravenous histamine, gives support to the suggestion that peripheral airways may contribute to lung recoil measurements in humans. 
In conclusion, we wish to point out that in many asthmatic patients in clinical remission there is evidence of reduced lung elastic recoil which contributes to reduced airflow measurements in such patients. It is possible that muscle tone in the peripheral airways underlies the changes observed.

We thank Dr $\mathbf{N} R$ Anthonisen for his constructive criticism in the preparation of this paper.

\section{References}

1 Gold WM, Kaufman HS, Nadel JA. Elastic recoil of the lungs in chronic asthmatic patients before and after therapy. J Appl Physiol 1967; 23:433-8.

2 Finucane KD, Colebatch HJH. Elastic behavior of the lungs in patients with airway obstruction. J Appl Physiol 1969; 26:330-8.

3 Manswell A, Dubrawsky C, Levison $\mathrm{H}$ et al. Lung mechanics in antigen-induced asthma. J Appl Physiol 1974; 37:297-301.

4 Woolcock AJ, Read J. The static elastic properties in the lungs in asthma. Am Rev Respir Dis 1968; 98:788-94.

5 Cherniack RM, Raber MB. Normal standards for ventilatory function using an automated wedge spirometer. Am Rev Respir Dis 1972; 106: 38-46.
6 DuBois AB, Botelho SY, Bedell GN, Marshall R, $\overrightarrow{\bar{N}}$ Comroe JH Jr. A rapid plethysmographic method for measuring thoracic gas volume: a $\frac{\overline{0}}{0}$ comparison with a nitrogen washout method for $\overline{\bar{w}}$ measuring functional residual capacity in normal $\overrightarrow{\mathbb{D}}$ subjects. J Clin Invest 1956; 35:322-6.

7 Milic-Emili J, Mead J, Turner JM, Glauser EM. ڤ Improved technique for estimating pleural $\vec{\circ}$ pressure from esophageal balloons. $J A p p l-$ Physiol 1964; 19:207-11.

8 Mead J, Turner JM, Macklem PT, Little JB. Significance of the relationship between lung $\vec{x}$ recoil and maximum expiratory flow. J Appl Physiol 1967; 22:95-108.

9 Peress L, Sybrecht G, Macklem PT. The î mechanism of increase in total lung capacity $@$ during acute asthma. Am J Med 1976; 61:165-9.

10 McFadden ER, Newton-Howes J, Pride NB. Acute effects of inhaled isoproterenol on the $>$ mechanical characteristics of the lungs in normal ․․․ man. J Clin Invest 1970; 49:779-90.

11 Colebatch HJH. The humoral regulation of $\vec{\oplus}$ alveolar ducts. In: Bouhouys A (ed). Airway. Dynamics. Springfield, Illinois: Charles C Thomas, 1970; 169-89.

12 Laitinen LA, Empey DW, Poppius H, Lemen RJ, Gold WM, Nadel JA. Effects of intravenous histamine on static lung compliance and airway resistance in normal man. Am Rev Respir Dis 1976; 114:291-5. 